\title{
The bioactive compounds of probiotic foods/supplements and their application in managing mental disorders
}

\author{
Crystal Leem ${ }^{1,2}$ and Danik M. Martirosyan ${ }^{1}$
}

${ }^{1}$ Functional Food Center, Dallas, TX, 75254, USA; ${ }^{2}$ Biola University, Department of Biological Sciences, La Mirada, CA, 90639, USA

Corresponding author: Danik M. Martirosyan, Functional Food Institute, Dallas, TX 75252, USA

Submission Date: September $7^{\text {th }}, 2019$. Acceptance Date: October $27^{\text {th }}, 2019$. Publication Date: October 30 $0^{\text {th }}, 2019$.

Citation: Leem C and Martirosyan DM. The bioactive compounds of probiotic foods/supplements and their application in managing mental disorders. Bioactive Compounds in Health and Disease 2019; 2(10): 206-220. DOI: https://doi.org/10.31989/bchd.v2i10.431

\begin{abstract}
Background: Probiotics have recently become popular among all generations, ranging from children to the elderly. They are living microorganisms known to improve gut flora by establishing and maintaining gut health via molecular mechanisms that involve various bioactive compounds produced and released throughout the body, which may cause a bacteria-host interaction. These bioactive compounds of probiotics may be bacteria or other compounds that are associated with various neurotransmitters, which produce different actions on the body. Changes in gut microbiota composition have been associated with various diseases, including mental disorders such as Alzheimer's/dementia, Parkinson's, schizophrenia, stress, anxiety, and depression. Clinical reviews and studies on both animals and humans have given mixed results regarding the efficacy of probiotic foods and supplements in managing mental disorders. In our review, we advocate for probiotic foods to be functional foods, but we are unable to accept probiotics as an effective treatment for the management of mental disorders due to indeterminate evidence.
\end{abstract}

Keywords: Probiotics, bioactive compounds, mental disorders, Alzheimer's disease, dementia, Parkinson's, schizophrenia, stress, anxiety, and depression

\section{HISTORY}

The consumption of fermented foods can be traced throughout history back to ancient civilizations, before even the era of Phoenicia. Cheese and fermented milk were favorites among the Greeks and Romans, and food such as bread and drinks like wine can be dated back to what many sacred texts consider the beginning of time [1]. Fermentation is an anaerobic process where bacteria convert sugar into lactic acid, which acts as a preservative [2]. While these ancient peoples were unaware of what was fermenting their food, they learned from observation that they could control the length of time that certain foods would ferment before they could eat and still enjoy them.

Elie Metchnikoff, also known as the father of modern probiotics, demonstrated in the early 20th century that regular consumption of lactic acid bacteria in fermented dairy products was 
associated with enhanced health and longevity in Bulgarian peasant populations [3]. This inspired scientists to conduct more research on the microbiology of human processes.

The term "probiotics" was first used in 1953 by Werner Kollath, who derived the word from the Greek words, "pro", meaning "for", and "biotos", meaning "life". In 1965, Lilly and Stillwell defined probiotics as "substances secreted by one organism which stimulate the growth of another" [4]. 9 years later, Parker described probiotics as "organisms and substances which contribute to intestinal microbial balance." 15 years later, Fuller proposed that probiotics are "live microbial supplements which beneficially affect the host animal by improving its microbial balance." As research in probiotics became more prevalent, a consensus definition of probiotics was adopted in 2001 by the United Nations Food and Agriculture Organization (FAO) and the World Health Organization (WHO) [5]. With a minor adjustment, the 2001 definition still holds true today. Probiotics are currently defined as "live organisms that, when administered in adequate amounts, confer a health benefit to the host" [6].

Because of the health benefits that probiotics offer, they are considered to be a functional food by many. While there is no official definition for the term "functional foods", the Functional Food Center (FFC) defines them as "natural or processed foods that contain biologically active compounds; which, in defined, effective non-toxic amounts, provide a clinically proven and documented health benefit utilizing specific biomarkers for the prevention, management, or treatment of chronic disease or its symptoms" [7].

The objective of this review is to examine recent findings on the bioactive compounds in probiotics and how they can be used to manage mental disorders.

\section{BIOMARKERS OF PROBIOTICS}

Probiotics contain biologically active organisms in them, such as bacteria or yeasts. Probiotic foods most commonly contain the Gram-positive lactic acid bacteria Lactobacillus and Bifidobacterium [8]. Other bacteria such as Lactococcus, Bacillus, Pediococcus, and Streptococcus are also used in probiotic research today [9, 10]. Main yeasts, such as Saccharomyces, have also been studied (table 1), along with other genera such as Kluyveromyces, Pichia, and Candida [11].

Table 1. Commonly used probiotic bacteria and their known functions in the foods these genera are found in.

\begin{tabular}{|c|c|c|}
\hline BACTERIA & FUNCTIONS & ASSOCIATED FOOD \\
\hline $\begin{array}{l}\text { Lactobacillus } \\
\qquad \begin{array}{l}\text { Lactococcus } \\
\text { Enterococcus } \\
\text { Oenococcus } \\
\text { Pediococcus } \\
\text { Streptococcus } \\
\text { Leuconostoc [79] }\end{array}\end{array}$ & $\begin{array}{l}\text { Convert hexose sugars to lactic acid, } \\
\text { inhibiting growth of harmful bacterial species }\end{array}$ & $\begin{array}{l}\text { Yogurt, cheese, sauerkraut, pickles, } \\
\text { sourdough, wine }\end{array}$ \\
\hline $\begin{array}{l}\text { Bifidobacterium strains [79- } \\
\text { 81] }\end{array}$ & $\begin{array}{l}\text { Resistant to bile salts, important in probiotic } \\
\text { bacteria survival Treat constipation, } \\
\text { diarrhea, colitis, and gut inflammation }\end{array}$ & $\begin{array}{l}\text { Fermented dairy products such as } \\
\text { milk and kefir }\end{array}$ \\
\hline Saccharomyces strains [79] & $\begin{array}{l}\text { Treat diarrhea, IBS, IBD, and ulcerative and } \\
\text { pseudomembranous colitis }\end{array}$ & Wine, bread, beer, kefir, kombucha \\
\hline
\end{tabular}




\section{Established Major Mechanisms of Action of Probiotics}

The specific mechanisms of various probiotics are still widely unknown. However, they are related antagonistically to the positive affects gut microbiota and other microorganisms, through various mechanisms, as elucidated below by Bermudez-Brito et al. [78].

Major mechanisms of the actions of probiotics:

1. Enhancement of the epithelial barrier

2. Increased adhesion to intestinal mucosa

3. Inhibition of pathogen adhesion

4. Competitive exclusion of pathogenic microorganisms

5. Production of antimicrobial substances

6. Modulation of the immune system

These mechanisms, while extensively studied, still require further detail before probiotics can be safely consumed as functional food products. It is understandable to then, examine the effect of gut bacteria on the rest of the body, particularly the brain, which controls many autonomic and non-autonomic functions.

\section{THE GUT-BRAIN AXIS}

In the last decade or so, the concept of the "gut-brain axis" has been heavily researched. Surprisingly, this concept has actually been in existence for over 200 years, starting from the 19th century [22]. A connection between intestinal health and mental health, as demonstrated by the gut-brain axis, suggests huge potential implications for the management and regulation of mental disorders via probiotic supplementation.

The gut-brain axis (GBA) refers to a bidirectional communication between the central and enteric nervous system, linking emotional and cognitive centers of the brain with peripheral intestinal functions, which can be seen within table 2 [23]. The idea of a gut-brain axis was first conceived in 1765, when Scottish physician Robert Whytt developed the concept of "nervous sympathy" to describe the holistic mechanisms by which internal organs communicated with each other [24]. Nineteenth century models of the gut-brain axis asserted that digestive dysbiosis caused dysfunction in emotions [22]. Particularly in 19th century England, indigestion was dubbed the national disease of the country, most likely due to poor and/or varying diets resulting from rapid industrialization and urbanization [25]. As the nineteenth century came to a close, scientists leaned more towards a reductionist approach, but realized that it could not explain clinical phenomena such as stomach problems resulting from violent or depressing events [26].

Today, we now know that the gut-brain axis' role is to monitor and integrate gut function as well as to link emotional and cognitive centers of the brain with peripheral intestinal functions and mechanisms [23]. We know this is due to the many studies that researchers have published with the aim of more fully examining the extent of the gut-brain axis' impact on mental health.

\section{Mechanisms of the Gut-Brain Axis}

The central nervous system (CNS), autonomic nervous system (ANS), enteric nervous system (ENS), and the limbic system all participate in the communication that occurs on the gut-brain 
axis. Pro-inflammatory cytokines activate the limbic system through secretion of the corticotropinreleasing factor (CRF), which leads to the release of cortisol from the adrenal glands [41]. Essentially, this shows that neural and hormonal lines allow the brain to influence the activities of intestinal functional effector cells while these cells are also under the influence of the gut microbiota [42]. Currently, there is no consensus on the mechanisms by which probiotics work specifically on the gut-brain axis. There is some evidence to believe that they may involve modifying gut $\mathrm{pH}$, antagonizing pathogens through production of antimicrobial compounds, stimulating immunomodulatory cells, and competing for pathogen binding sites as well as nutrients and growth factors [47].

Table 2. Bacteria commonly found in the human gut microbiome and the neurotransmitters they communicate with.

\begin{tabular}{|c|c|c|c|}
\hline STUDY & $\begin{array}{l}\text { BIOACTIVE } \\
\text { COMPOUND }\end{array}$ & NEUROTRANSMITTER & OUTCOME \\
\hline $\begin{array}{l}\text { Komatsuzaki, et } \\
\text { al. [82] }\end{array}$ & Lactobacillus & GABA & $\begin{array}{l}\text { Lactobacillus in fermented fish } \\
\text { produced } 302 \mathrm{mM} \text { of GABA from } \\
500 \mathrm{mM} \text { of glutamate in culture }\end{array}$ \\
\hline Coda, et al. [83] & Lactococcus & GABA & $\begin{array}{l}\text { Lactococcus in sourdough bread } \\
\text { produced } 504 \mathrm{mg} / \mathrm{kg} \text { of GABA }\end{array}$ \\
\hline Asano, et al. [84] & Escherichia coli & Norepinephrine & $\begin{array}{l}\text { Substantial levels of } \\
\text { norepinephrine were identified in } \\
\text { the gut and associated with } E \text {. coli }\end{array}$ \\
\hline $\begin{array}{l}\text { Barneound, et al. } \\
\text { [85] }\end{array}$ & $\begin{array}{l}\text { Mycobacterium } \\
\text { (Bacillus Calmette- } \\
\text { Guerin) }\end{array}$ & Norepinephrine & $\begin{array}{l}\text { Brain norepinephrine levels } \\
\text { increased after bacillus Calmette- } \\
\text { Guerin was injected }\end{array}$ \\
\hline Yano, et al. [35] & $\begin{array}{l}\text { Streptococcus, } \\
\text { Enterococcus }\end{array}$ & Serotonin & $\begin{array}{l}\text { These gut bacteria regulate } 64 \% \\
\text { of colonic and } 49 \% \text { of serum } \\
\text { serotonin concentrations }\end{array}$ \\
\hline $\mathrm{Hu}$, et al. [86] & Bacillus & Serotonin & $\begin{array}{l}\text { Plasma serotonin levels decreased } \\
\text { significantly from } 17 \text { to } 12 \mathrm{ng} / \mathrm{mL} \\
\text { in dominant hens after being fed } \\
\text { Bacillus subtilis for } 14 \text { days }\end{array}$ \\
\hline Das, et al. [87] & Escherichia coli & Dopamine & $\begin{array}{l}\text { E. coli } \mathrm{DH} 5 \alpha \text { produced } 27 \mathrm{mg} / \mathrm{L} \\
\text { of dopamine in growth media. } \\
\text { Synthesis was remarkably } \\
\text { enhanced in vivo. }\end{array}$ \\
\hline $\begin{array}{l}\text { Stephenson, et al. } \\
\text { [88] }\end{array}$ & Lactobacillus & Acetylcholine & $\begin{array}{l}\text { A strain of Lactobacillus found in } \\
\text { sauerkraut produced } \sim 5 \mu \mathrm{g} / \mathrm{mg} \text { dry } \\
\text { weight of cells } / \mathrm{hr}\end{array}$ \\
\hline
\end{tabular}


As the table (2) above shows, neurotransmitters are important chemicals by means of which communication via the gut-brain axis is possible.

Several studies describe other bioactive molecules that mediate communication between the brain and the gut, including short-chain fatty acids [34, 45], bile acids [45, 46], serotonin [35], and tryptophan metabolites [36]. Short-chain fatty acids represent the major flow of carbon from the microbiome to the host [37]. The essential amino acid tryptophan is known as the precursor of the neurotransmitter serotonin [38]. Numerous studies have shown that tryptophan and/or serotonin have an inhibitive effect on aggressive behavior and post-stress cortisol concentrations [39, 40].

In germ-free (GF) mice, risk-taking behaviors and hyperactivity increased while learning and memory skills decreased compared to standard pathogen-free (SPF) mice [27]. This may be due to the observation that germ-free mice exhibited an increased volume of the amygdala and hippocampus [28]. Germ-free mice also showed changes in expression of the 5-HT1A receptor, neurotrophic factors, and NMDA receptor subunits in the hippocampus [29-31], while also displaying impaired blood-brain barrier function [32] and increased myelination in the prefrontal cortex [33]. In these specific studies, neurophysiological changes can be seen.

It is clear to see that communication between the gut and brain is a concept that still requires much further study; however, current research seems promising. As earlier discussed, mental disorders/illnesses are burdening more and more people worldwide, up to 350 million people [48]. Probiotic supplementation can help with maintaining a properly functioning gut microbiota, which, in turn, can help with managing mental disorders.

\section{PROBIOTIC BACTERIA IN FOOD}

\section{Dairy Products}

For many, the first probiotics that come to mind are dairy products, such as yogurt and milk. These are the probiotics that have been mainly studied, and a meta-analysis done by Zhang et al. [13] indicated an association between fermented dairy foods intake and decreased cardiovascular disease, confirming that dairy products positively influence human health.

Dairy products typically contain Lactobacillus and Bifidobacterium, and more studies are being conducted to see the effects of these microorganisms in various settings. For example, Li et al. experimented with the bacteria Bifidobacterium breve in yogurt and found that it showed good stability in vitro and an increased survival rate, even when encapsulated with low methoxyl pectin [12]. Davras et al. found that the high probiotic content of kefir enabled modulation of many immunological mechanisms such as regulating IgA, IgG, IL-4, IL-10, and IL-12 levels [20]. On the other end of the spectrum, others have also observed that many probiotic foods failed to survive in high quantity, limiting their effectiveness as functional foods. Thus, Fazilah et al. [10] set out to increase survival rate by encapsulating Lactococcus lactis cells with gum arabic and Synsepalum dulcificum, which led to a higher viability than non-encapsulated cells. Much research has been conducted on how dairy products affect the human microbiome, and more is required to establish a consensus.

\section{Non-Dairy Products}

There are also other non-dairy foods that contain probiotic microorganisms. To name a few, there are dark chocolate, green peas, sauerkraut, kombucha, kimchi, beer/wine, green olives, natto, pickles, miso, sourdough bread, and tempeh [14]. In kimchi, Lactobacillus plantarum is an isolate 
that is the main focus of many researchers. Some of the benefits from consuming L. plantarum in kimchi are that they have antioxidant and immune-enhancing properties [16], help manage hypercholesterolemia [15], and have remedial potential against influenza viruses [18]. In sauerkraut, 114 isolates of bacteria were discovered, and $85 \%$ of those isolates belonged to the Lactobacillus and Leuconostoc genera [15]. Other studies found that despite low initial relative abundance, sauerkraut fermentation resulted in a stable and rapidly established community of lactic acid bacteria that certainly met the recommended CFU range for probiotics [19, 20]. In fermented tuna viscera, $H$. elongata, a bacterium able to remove heavy metals in hypersaline environments and T. halophilus, a lactic acid bacterium, together were capable of the removal of heavy metals, such as $\mathrm{Cd}, \mathrm{Pb}$, and $\mathrm{Hg}$, in SNB and MRS broth [21]. These studies show the diverse health benefits that non-dairy probiotic foods have to offer, illuminating probiotics as a potential functional food.

\section{The FFC's Standards for Identifying Functional Foods}

The FFC goes through a systematic evaluation when identifying functional foods. The steps are as follows [7]:

1. Examine the link between a particular food and its health benefits.

2. Determine the bioactive compound(s) responsible for observed health benefits by running in vitro and in vivo studies on both non-living and living specimens.

3. Use in vitro and in vivo studies to determine the mechanism of action by which bioactive compound(s) impart health benefits.

4. Establish daily value that will deliver effective health benefits to consumer while avoiding toxicity.

5. Conduct human studies to determine proper dosage of bioactive compound(s).

6. Develop appropriate food vehicle to combine with bioactive compound(s), resulting in the creation of a functional food product.

7. Ensure proper regulations are met and administer final product to the public.

Once these standards have been met, probiotic foods would be considered functional foods. It is important to notice that one of the most important parts of these steps is the emphasis on bioactive compounds as they appear within four different steps. Bioactive compounds within probiotics can be found within table 2 , which shows what bioactive compounds produce or are associated with various neurotransmitters. Without identifying the bioactive compound, there would be minimal evidence of the properties of the food and would make it difficult to define it as functional. With the certain bioactive compounds discovered within probiotics, there are now many exciting applications for probiotics which have yet to be fully and extensively studied, including the potential mental health benefits probiotics confer.

\section{THE IMPACT OF PROBIOTICS ON MENTAL DISORDERS}

As early as 2001, the World Health Organization (WHO) determined that 1 in 4 people across the globe would be affected by mental or neurological disorders at some point in their lives [43]. As of 2017, the American National Institute of Mental Health (NIMH) reported that nearly 1 in 5 U.S. adults lived with a mental illness. According to the NIMH, a mental illness is defined as a mental, behavioral, or emotional disorder [44]. Various studies have studied various bioactive compounds 
within probiotics and observed communications with different neurotransmitters (table 2). These neurotransmitters, including glutamate, GABA, serotonin, dopamine, and norepinephrine, have been associated with mental illnesses. For example, people who suffer from depression have been observed to release lower amounts of serotonin than those who do not [89]. Studies by Yano et al. and $\mathrm{Hu}$ et al. observed bioactive compounds within probiotics communicate with the serotonin neurotransmitter and affected the levels of serotonin concentration (table 2). In future studies, this could be utilized to increase serotonin levels and thus decrease depressive symptoms. With probiotics having an effect on neurotransmitters within the gut-brain axis and due to the recent abundance of published studies, it is feasible to analyze the effects of probiotic intake on a variety of mental illnesses.

\section{Stress, Anxiety, and Depression}

Stress is an emotional or mental strain that results from adverse circumstances. In order to study the effects of probiotics on stress, researchers induced early life stress on infant rats and caused early expressions of adult-like fear memory retention. Administration of a probiotic supplement, Lacidofil, not only prevented the transition to adult-like fear memory retention, but also decreased anxiety-like behavior and increased neurotrophic factor protein levels in the basolateral nucleus of the amygdala [53]. This suggests a potential therapeutic effect that may occur for children who experience similar early life stress. In rugby athletes, probiotic supplementation over 27 weeks also resulted in a significantly higher salivary cortisol and salivary alpha-amylase in the probiotic group versus the placebo group [54].

Anxiety is clinically defined as a state of excessive uneasiness and apprehension, typically with compulsive behavior or panic attacks. In one study, 86 college students consumed probiotics every day for 28 days, and there were improvements in panic anxiety, neurophysiological anxiety, worry, and mood regulation [55]. In another study, 111 stressed adults consumed Lactobacillus plantarum daily for 12 weeks, which significantly reduced symptoms of stress and anxiety compared to the placebo group as early as 8 weeks [56].

According to the American Psychiatric Association, depression, also known as major depressive disorder, is a disease that causes feelings of sadness and/or a loss of interest in activities once enjoyed [52]. Jang et al. [55] found that Lactobacillus reuteri and Bifidobacterium adolescentis synergistically suppressed occurrence and development of anxiety/depression by a significant amount. Most of the above studies make a case in support of probiotic supplementation as a way to manage stress, anxiety, and/or depression.

\section{Schizophrenia}

Mayo Clinic describes schizophrenic patients as those who interpret reality abnormally; they can display symptoms ranging from hallucinations, delusions, and disordered thinking and behavior that impairs daily functioning and can be disabling [49]. People with schizophrenia require lifelong care, but their symptoms can potentially be managed by daily intake of probiotics.

A study conducted in 2017 examined 2 schizophrenic patients' fecal secondary bile acid levels in order to observe the influence of probiotics on these 2 patients [46]. While it seemed that Lactobacillus rhamnosus appeared to promote bile acid deconjugation, most of the unconjugated bile acids appeared to be modified into secondary bile acids, and there was no significant change. Another study from 2017 revealed an association between probiotic intake and lower levels of 
Candida albicans, but in males only [51]. A review done in early April of this year analyzed 3 studies that compared the use of probiotics to placebo controls. Separate analyses on the effect of probiotic supplementation on positive or negative symptoms of schizophrenia were also run, but there was no significant difference observed throughout the review [50]. The above studies are inconclusive, and more research is necessary in order to come to a unified opinion regarding the effect of probiotics on schizophrenia.

\section{Autism}

Autism spectrum disorder (ASD) refers to a range of conditions characterized by challenges with social skills, repetitive, speech and nonverbal communication [58]. Some symptoms are: making little to no eye contact, rarely sharing enjoyment of objects with others, having difficulty maintaining a conversation, having an unusual tone of voice, contradictory expressions to what is being said, having overly focused interests, repeating unusual behaviors, and being sensitive to sensory input [63].

In one study, lower bacterial diversity was observed in toddlers with ASD compared to healthy controls [59]. Prevotella, a bacterial genera involved in saccharide metabolism [60] and vitamin biosynthesis [61], was found to be in particularly low concentrations. Seeing that autistic individuals are thought to have impaired carbohydrate digestion [62], consumption of Prevotella may be beneficial. In another study, children with autistic symptoms and gastrointestinal distress were given Delpro, a mixture of 5 probiotic strains, for 21 days. $88 \%$ of parents whose children participated in the study reported improvements in symptoms [64]. Probiotics may help manage the gastrointestinal symptoms associated with autism, but more research must be conducted in order to achieve full understanding of the underlying mechanism leading to such a result.

\section{Alzheimer's, Parkinson's, and Dementia}

Alzheimer's and Parkinson's disease, as well as dementia, are memory loss diseases. The symptoms for all 3 diseases are caused by the destruction of brain cells, which can also lead to behavioral changes [65]. According to the National Institute of Aging (NIA), dementia is a brain disorder that affects communication and daily activity while Alzheimer's is a form of dementia that specifically affects thought and memory [66]. Parkinson's is considered by the NIA to be a brain disorder that leads to shaking, stiffness, and difficulty in walking, balance, and coordination [67].

Mild cognitive impairment, a condition where individuals experience more memory problems than normal, is regarded as a possible precursor to Alzheimer's [68]. Early intervention using Lactobacillus plantarum-fermented soybeans was found to improve cognitive functions after consumption of L. plantarum ( $\mathrm{p}=0.02$ ) [69]. In another study, Alzheimer's patients were divided into a treatment group (3 species of Lactobacillus and 3 species of Bifidobacterium) and placebo group, and neither ANOVA tests nor t-tests indicated any statistical difference between the two groups [70]. Results of another study showed that kynurenine serum levels significantly increased after probiotic supplementation in Alzheimer's patients, but this did not lead to a significant change in Kyn/Trp concentration [71]. These studies, while inconclusive, pave the way for future clinical studies on the effects of probiotics on neurodegenerative diseases. 
Table 3. Efficacy of probiotics on various mental disorders (summary of studies above).

\begin{tabular}{|c|c|c|c|c|}
\hline STUDY & $\begin{array}{l}\text { MENTAL } \\
\text { DISORDER }\end{array}$ & PROBIOTIC(S) & RESULT & IMPACT \\
\hline [53] & Stress & Lacidofil (Lactobacillus) & $\begin{array}{l}\text { Decreased anxiety-like } \\
\text { behavior, seen in amygdala }\end{array}$ & Decrease in anxiety \\
\hline [56] & Anxiety & Lactobacillus plantarum & $\begin{array}{l}\text { Stressed adults } \\
\text { experienced a significant } \\
\text { decrease in stress/anxiety } \\
\text { symptoms }\end{array}$ & $\begin{array}{l}\text { Decrease in symptoms } \\
\text { of stress and anxiety }\end{array}$ \\
\hline [57] & Depression & $\begin{array}{l}\text { Lactobacillus reuteri, } \\
\text { Bifidobacterium } \\
\text { adolescentis }\end{array}$ & $\begin{array}{l}\text { Significantly suppressed } \\
\text { occurrence and } \\
\text { development of } \\
\text { anxiety/depression }\end{array}$ & $\begin{array}{l}\text { Decrease in frequency } \\
\text { and development of } \\
\text { anxiety/depression }\end{array}$ \\
\hline $\begin{array}{l}{[46],} \\
{[51]}\end{array}$ & Schizophrenia & $\begin{array}{l}\text { [46]: Lactobacillus } \\
\text { rhamnosus } \\
\text { [51]: Saccharomyces } \\
\text { cerevisiae }\end{array}$ & $\begin{array}{l}\text { [46]: Significant increase } \\
\text { in secondary bile acid } \\
\text { levels in only } 1 \text { of } 2 \\
\text { patients } \\
\text { [51]: Significant decrease } \\
\text { in C. albicans in } \\
\text { schizophrenic males only }\end{array}$ & $\begin{array}{l}\text { Inconclusive; } \\
\text { mixed significant } \\
\text { changes in behavioral } \\
\text { symptoms }\end{array}$ \\
\hline [64] & Autism & $\begin{array}{l}\text { Delpro (Lactobacillus } \\
\text { rhamnosus) }\end{array}$ & $\begin{array}{l}88 \% \text { of parents with } \\
\text { autistic children in study } \\
\text { reported improvement in } \\
\text { symptoms }\end{array}$ & $\begin{array}{l}\text { Decrease in autistic } \\
\text { symptoms }\end{array}$ \\
\hline $\begin{array}{l}{[69],} \\
{[70]}\end{array}$ & $\begin{array}{l}\text { Alzheimer's } \\
\text { Parkinson's } \\
\text { Dementia }\end{array}$ & $\begin{array}{l}\text { [69]: Lactobacillus } \\
\text { plantarum } \\
\text { [70]: Lactobacillus and } \\
\text { Bifidobacterium }\end{array}$ & $\begin{array}{l}\text { [69]: Fermented soybeans } \\
\text { significantly improved } \\
\text { cognitive function } \\
\text { [70]: No statistical } \\
\text { difference between placebo } \\
\text { and treatment }\end{array}$ & $\begin{array}{l}\text { Inconclusive; mixed } \\
\text { significance }\end{array}$ \\
\hline
\end{tabular}

\section{ADVERSE SIDE EFFECTS}

The National Center for Complementary and Integrative Health (NCCIH) has stated that generally healthy individuals can usually experience mild digestive symptoms such as gas, but nothing worse [3]. However, for individuals with underlying medical problems such as weak immune systems, dangerous infections may arise, and so it is important to exercise caution before accepting foreign microorganisms, such as those in probiotic foods, into the body [3].

Too much consumption of probiotics may lead to bloating, gas, diarrhea, and abdominal pain [72]. Yeast-based probiotics may result in constipation and/or increased thirst [73]. An overabundance of D-lactic acid may also cause temporary confusion, due to its toxicity against human brain cells and potential to cause lactic acidosis [74]. One study even outlines the potential 
development of probiotic bacteria into harmful, antibiotic-resistant bacteria [75]. The adverse side effects suggest that healthy individuals should consume probiotic foods/supplements regularly but not too often, and that those with weak immunity should not consume probiotics at all.

\section{CONCLUSION}

The question of how effective probiotics are in managing mental disorders remains unresolved. However, since microorganisms that colonize the gut microbiota have been shown to modulate immune response, mood, and behavior by communicating to the brain via the gut-brain axis, they should be continued to be researched. Similarly, when probiotics are consumed, they affect the intestinal microbiome and brain in complex mechanisms that still requires much study. The first step necessary to fuel more research seems to be validating probiotic foods as functional foods, and to raise the awareness of the scientific community regarding the significance of probiotic bacteria in food. Furthermore, probiotics should be put into more foods for future studies. It is essential to examine the effects of different probiotic supplements mixed into food and of foods naturally containing bacteria. Finally, the standardization of experimental design amongst various research labs would have great potential in obtaining replicable and conclusive data.

\section{REFERENCES}

1. Gismondo, M.R., Drago, L., Lombardi, A.: Review of probiotics available to modify gastrointestinal flora. Int. J. Antimicrob. Ag. 1999, 12(4): 287-292.

2. Blaber, M, Benson, D: Fermentation. Chemistry LibreTexts, Libretexts. 2019.

3. Probiotics: In Depth - National Institutes of Health [https://nccih.nih.gov/ health/probiotics/introduction.htm]

4. Gupta, V, Garg, R: Probiotics. Indian J. Med. Microbiol. 2009, 27(3): 202-209.

5. Food Safety and Quality Probiotics- Food and Agricultural Organization [http://www.fao.org/food/food-safety-quality/a-z-index/probiotics/en/]

6. Definition of Probiotics: 12 Years Later- California Dairy Research Foundation [http://cdrf.org/2014/06/10/definition-probiotics-12-years-later/]

7. Gur, J., Mawuntu, M., Martirosyan, D.: FFC's Advancement of Functional Food Definition. Funct. Foods Health Dis. 2018, 8(7): 385-397.

8. Nath, A., Haktanirlar, G., Varga, A., Molnar, M.A., Albert, K., Galambos, I., Koris, A, et al.: Biological Activities of Lactose-Derived Prebiotics and Symbiotic with Probiotics on Gastrointestinal System. Medicina (Kaunas). 2018, 54(2): 18.

9. Luo, G., Li, B., Yang, C., Wang. Y., Bian, X., Li, W., Liu, F., et al.: Major Traditional Probiotics: Comparative Genomic Analyses and Roles in Gut Microbiome of Eight Cohorts. Front. Microbiol. 2019. DOI: https://doi.org/10.3389/fmicb.2019.00712.

10. Fazilah, N.F., Hamidon, N.H., Ariff, A.B., Khayat, M.E., Wasoh, H., Halim, M.: Microencapsulation of Lactococcus lactis Gh1 with Gum Arabic and Synsepalum dulcificum via Spray Drying for Potential Inclusion in Functional Yogurt. Molecules. 2019, 24(7): 1422.

11. Menezes A.G.T., Ramos C.L., Cenzi G., Melo D.S., Dias D.R., Schwan R.F.: Probiotic Potential, Antioxidant Activity, and Phytase Production of Indigenous Yeasts Isolated from Indigenous Fermented Foods. Probiotics Antimicrob. Proteins. 2019, 1-9. 
12. Li M., Jin Y., Wang Y., Meng L., Zhang N., Sun Y., Hao J., et al.: Preparation of Bifidobacterium breve encapsulated in low methoxyl pectin beads and its effects on yogurt quality. J. Dairy Sci. 2019, 102(6): 4832-4843.

13. Zhang K., Chen X., Zhang L., Deng Z.: Fermented dairy foods intake and risk of cardiovascular diseases: A meta-analysis of cohort studies. Crit. Rev. Food Sci. Nutr. Tarantino, O, 2016.

14. Probiotic Foods for a Healthy Gut [https://www.eatthis.com/ best-probiotic-foods/]

15. Touret T., Oliveira M., Semedo-Lemsaddek T.: Putative probiotic lactic acid bacteria isolated from sauerkraut fermentations. PLoS ONE. 2018, 13(9): e0203501.

16. Yang S.J., Lee J.E., Lim S.M., Kim Y.J., Lee N.K., Paik H.D.: Antioxidant and immuneenhancing effects of probiotic Lactobacillus plantarum 200655 isolated from kimchi. Food Sci. Biotechnol. 2018, 28(2): 491-499.

17. Heo W., Lee E.S., Cho H.T., Kim J.H., Lee J.H., Yoon S.M., Kwon H.T., et al.: Lactobacillus plantarum LRCC 5273 isolated from kimchi ameliorates diet-induced hypercholesterolemia in C57BL/6 mice. Biosci. Biotechnol. Biochem. 2018, 82(11): 19641972.

18. Park, S., Kim, J.I., Bae, J.Y., Yoo, K., Kim, H., Kim, I.H., Park, M.S., Lee, I.: Effects of heat-killed Lactobacillus plantarum against influenza viruses in mice. J. Microbiol. 2018, 56(2): 145-149.

19. Zabat, M.A., Sano, W.H., Wurster, J.I., Cabral, D.J., Belenky, P: Microbial community analysis of sauerkraut fermentation reveals a stable and rapidly established community. Foods. 2018, 7(5): E77.

20. Orgeron II, R., Corbin, A., Scott, B.: Sauerkraut: A Probiotic Superfood. Funct. Foods Health. Dis. 2016, 6(8): 536-543.

21. Asksonthong, R., Siripongvutikorn, S., Usawakesmanee, W: Evaluation of heavy metal $(\mathrm{Hg}, \mathrm{Pb}$, and $\mathrm{Cd})$ reduction using Halomonas elongata and Tetragenococcus halophilus for protein hydrolysate product. Funct. Foods Health Dis. 2016, 6(4): 195-205.

22. Miller I.: The gut-brain axis: historical reflections. Microb. Ecol. Health Dis. 2018, 29(1): 1542921.

23. Carabotti, M., Scirocco, A., Maselli, M.A., Severi, C: The gut-brain axis: interactions between enteric microbiota, central and enteric nervous systems. Ann. Gastroenterol. 2015, 28(2): 203-209.

24. Whytt, R: Observations on the Nature, Causes, and Cure of Those Disorders Which Have Been Commonly Called Nervous, Hypochondriac, or Hysteric. T. Becket, P. Du Hondt, London, and J. Balfour, Edinburgh. 1765.

25. Baillie M: Dr. Baillie's Posthumous Works. Med. Chir. Rev. 1826, 4(8): 364-379.

26. Cannon W.B: The Influence of Emotional States on the Functions of the Alimentary Canal. Am. J. Med. Sci. 1909, 137(4): 480.

27. Sharon, G., Sampson, T.R., Geschwind, D.H., Mazmanian, S.K: The Central Nervous System and the Gut Microbiome. Cell. 2016, 167(4): 915-932.

28. Luczynski, P., Whelan, S.O., O’Sullivan, C., Clarke, G., Shanahan, F., Dinan, T.G., Cryan, J.F: Adult microbiota-deficient mice have distinct dendritic morphological changes: 
differential effects in the amygdala and hippocampus. Eur. J. Neurosci. 2016, 44(9): 26542666.

29. Bercik, P., Denou, E., Collins, J., Jackson, W., Lu, J., Jury, J., Deng, Y., et al.: The intestinal microbiota affects central levels of brain-derived neurotropic factor and behavior in mice. Gastroenterology. 2011, 141(2): 599-609.

30. Hejitz, R.D., Wang, S., Anuar, F., Qian, Y., Bjorkholm, B., Samuelsson, A., Hibberd, M.L., et al: Normal gut microbiota modulates brain development and behavior. Proc. Natl. Acad. Sci. USA. 2011, 108(7): 3047-3052.

31. Sudo, N., Chida, Y., Aiba, Y., Sonoda, J., Oyama, N., Yu, X., Kubo, C., et al.: Postnatal microbial colonization programs the hypothalamic-pituitary-adrenal system for stress response in mice. J. Physiol. 2004, 558(Pt 1): 263-275.

32. Braniste, V., Al-Asmakh, M., Kowal, C., Anuar, F., Abbaspour, A., Toth, M., Korecka, A., et al: The gut microbiota influence blood-brain barrier permeability in mice. Sci. Transl. Med. 2014, 6(263): 263ra158.

33. Hoban, A.E., Stilling, R.M., Ryan, F.J., Shanahan, F., Dinan, T.G., Claesson, M.J., Clarke, G., et al.: Regulation of prefrontal cortex myelination by the microbiota. Transl. Psychiatry. . 2016, DOI: 10.1038/tp.2016.42.

34. Tolhurst, G., Heffron, H., Lam, Y.S., Parker, H.E., Habib, A.M., Diakogiannaki, E: Cameron, J., et al.: Short-Chain Fatty Acids Stimulate Glucagon-Like Peptide-1 Secretion viz the G-Protein-Coupled Receptor FFAR2. Diabetes. 2012, 61(2): 364-371.

35. Yano, J.M., Yu, K., Donaldson, G.P., Shastri, G.G., Ann, P., Ma, L., Nagler, C.R., et al.: Indigenous bacteria from the gut microbiota regulate host serotonin biosynthesis. Cell. 2015, 161(2): 264-276.

36. Wikoff, W.R., Anfora, A.T., Liu, J., Schultz, P.G., Lesley, S.A., Peters, E.C., Siuzdak, G: Metabolomics analysis reveals large effects of gut microflora on mammalian blood metabolites. Proc. Natl. Acad. Sci. USA. 2009, 106(10): 3698-3703.

37. Morrison D.J. and Preston T: Formation of short chain fatty acids by the gut microbiota and their impact on human metabolism. Gut Microbes. 2016, 7(3): 189-200.

38. Hoglund. E., Overli, O., Winberg, S.: Tryptophan Metabolic Pathways and Brain Serotonergic Activity: A Comparative Review. Front. Endocrinol. 2019, 10:158.

39. Yoshida, K., Drew, M.R., Mimura, M., Tanaka, K.F.: Serotonin-mediated inhibition of ventral hippocampus is required for sustained goal-directed behavior. Nat. Neurosci. 2019, 22(5): 770-777.

40. Jenkins, T.A., Nguyen, J.C.D., Polglaze, K.E., Bertrand, P.P: Influence of Tryptophan and Serotonin on Mood and Cognition with a Possible Role of the Gut-Brain Axis. Nutrients. 2016, 8(1): 56.

41. Carabotti, M., Scirocco, A., Maselli, M.A., Severi, C: The gut-brain axis: interactions between enteric microbiota, central and enteric nervous systems. Ann. Gastroenterol. 2015, 28(2): 203-209.

42. Mayer, E.A., Savidge, T., Shulamn, R.J: Brain-gut microbiome interactions and functional bowel disorders. Gastroenterology. 2014, 146(6): 1500-1512.

43. Mental disorders affect one in four people -World Health Report [https://www.who.int/ 
whr/2001/media_centre/press_release/en/]

44. Mental Illness- National Institute of Mental Health (NIH) [https://www.nimh.nih. gov/health/statistics/mental-illness.shtml]

45. Dinan, T.G., Stilling, R.M., Stanton, C., Cryan, J.F: Collective unconscious: how gut microbes shape human behavior. J. Psychiatr. Res. 2015, 63: 1-9.

46. Saito, Y., Nishimiya, H., Kondo, Y., Sagae, T: The influence of probiotics on individual fecal secondary bile acid levels: a two-case study of schizophrenic patients receiving an atypical antipsychotic drug. Funct. Foods Health. Dis. 2017, 7(11): 849-858.

47. Parvez, S., Malik, K.A., Kang, S.A., Kim, H.Y: Probiotics and their fermented food products are beneficial for health. J. Appl. Microbiol. 2006, 100(6): 1171-1185.

48. Tucci, V. and Moukaddam, N.: We are the hollow men: The worldwide epidemic of mental illness, psychiatric and behavioral emergencies, and its impact on patients and providers. $J$. Emerg. Trauma Shock. 2017, 10(1): 4-6.

49. Schizophrenia symptoms and causes - Mayo Clinic [https://www.mayoclinic.org/diseasesconditions/schizophrenia/symptoms-causes/syc-20354443]

50. Ng, Q.X., Soh, A.Y.S., Venkatanarayanan, N., Ho, C.Y.X., Lim, D.Y., Yeo, W.S: A Systematic Review of the Effect of Probiotic Supplementation on Schizophrenia Symptoms. Neuropsychobiology. 2019, 78(1): 1-6.

51. Severance, E.G., Gressitt, K.L., Stallings, C.R., Katsafanas, E., Schweinfurth, L.A., Savage, C.L.G., Adamos, M.B., et al.: Probiotic normalization of Candida albicans in schizophrenia: A randomized, placebo-controlled, longitudinal pilot study. Brain Behav. Immun. 2017, 62: 41-45.

52. What is Depression?- American Psychiatric Association [https://www.psychiatry. org/patients-families/depression/what-is-depression]

53. Peng, H., Tsai, T., Huang, W., Wu, H., Hsu, K.: Probiotic treatment restores normal developmental trajectories of fear memory retention in maternally separated infant rats. Neuropharmacology. 2019, 153: 52-62.

54. Pumpa, K.L., McKune, A.J., Harnett, J.: A novel role of probiotics in improving host defence of elite rugby union athlete: A double blind randomised controlled trial. J. Sci. Med. Sport. 2019, 22(8): 876-881.

55. Tran, N., Zhebrak, M., Yacoub, C., Pelletier, J., Hawley, D.: The gut-brain relationship: Investigating the effect of multispecies probiotics on anxiety in a randomized placebocontrolled trial of healthy young adults. J. Affect. Disord. 2019, 252: 271-277.

56. Chong, H.X., Yusoff, N.A.A., Hor, Y., Lew, L., Jaafar, M.H., Choi, S., Yusoff, M.S.B., et al.: Lactobacillus plantarum DR7 alleviates stress and anxiety in adults: a randomised, double-blind, placebo-controlled study. Benef. Microbes. 2019, 10(4): 355-373.

57. Jang, H., Lee, K., Kim, D.: The Preventive and Curative Effects of Lactobacillus reuteri NK33 and Bifidobacterium adolescentis NK98 on Immobilization Stress-Induced Anxiety/Depression and Colitis in Mice. Nutrients. 2019, 11(4): 819.

58. What is Autism?- Autism Speaks. [https://www.autismspeaks.org/what-autism] 
59. Qiao, Y., Wu, M., Feng, Y. Zhou, Z., Chen, L., Chen, F: Alterations of oral microbiota distinguish children with autism spectrum disorders from healthy controls. Sci. Rep. 2019, 8: 1597.

60. Takahashi, N., Yamada, T: Glucose metabolism by Prevatolla intermedia and Prevotella nigrescens. Oral Microbiol. Immunol. 2001. DOI: https://doi.org/10.1034/j.1399-302x. 2000.150307.x.

61. Kang, D., Park, J.G., Ilhan, Z.E., Wallstrom, G., LaBaer, J., Adams, J.B., KrajmalnikBrown, R.: Reduced Incidence of Prevotella and Other Fermenters in Intestinal Microflora of Autistic Children. PLoS One. 2013, 8(7): e68322.

62. Williams, B.L., Hornig, M., Parekh, T., Lipkin, W.I.: Application of novel PCR-based methods for detection, quantitation, and phylogenetic characterization of Sutterella species in intestinal biopsy samples from children with autism and gastrointestinal disturbances. MBio. 2012, DOI: 10.1128/mBio.00261-11.

63. Autism Spectrum Disorder- National Institute of Mental Health [https://www.nimh.nih.gov/ health/topics/autism-spectrum-disorders-asd/index.shtml]

64. West, R., Roberts, E., Sichel, L.S., Sichel, J.: Improvements in Gastrointestinal Symptoms among Children with Autism Spectrum Disorder Receiving the Delpro® Probiotic and Immunomodulator Formulation. J. Prob. Health. 2013, 1(1): 102.

65. Alzheimer's and Parkinson's Disease: Similarities and Differences [https://www. brightfocus.org/alzheimers-disease/article/alzheimers-and-parkinsons-disease-similaritiesand-differences]

66. Alzheimer's Basics- National Institutes of Health (NIH) [https://www.nia. nih.gov/health/alzheimers/basics]

67. Parkinson's Disease- National Institutes of Health (NIH) [https://www.nia. nih.gov/health/parkinsons-disease]

68. What is Mild Cognitive Impairment?- National Institutes of Health (NIH) [https://www.nia. nih.gov/health/what-mild-cognitive-impairment]

69. Hwang, Y.H., Park, S., Paik, J.W., Chae, S.W., Kim, D.H., Jeong, D.G., Ha, E., et al.: Efficacy and Safety of Lactobacillus plantarum C29-Fermented Soybean (DW2009) in Individuals with Mild Cognitive Impairment: A 12-Week, Multi-Center, Randomized, Double-Blind, Placebo-Controlled Clinical Trial. Nutrients. 2019, 11(2): 305.

70. Agahi, A., Hamidi, G.A., Daneshvar, R., Hamdieh, M., Soheili, M., Alinaghipour, A., Taba, S.M.E., et al.: Does Severity of Alzheimer's Disease Contribute to Its Responsiveness to Modifying Gut Microbiota? A Double Blind Clinical Trial. Front. Neurol 2018, DOI:https://doi.org/10.3389/fneur.2018.00662.

71. Leblhuber, F., Steiner, K., Schuetz, B., Fuchs, D., Gostner, J.M.: Probiotic Supplementation in Patients with Alzheimer's Dementia - An Explorative intervention Study. Curr. Alzheimer Res. 2018, 15(12): 1106-1113.

72. Williams, N.T: Probiotics. Am. J. Health Syst. Pharm. 2010, 67(6): 449-458.

73. Karpa, K.D: Probiotics for Clostridium difficile diarrhea: putting it into perspective. Ann. Pharmacother. 2007, 41(7): 1284-1287. 
74. Rao, S., Rehman, A., Yu, S., de Andino, N: Brain fogginess, gas, and bloating: a link between SIBO, probiotics and metabolic acidosis. Clin. Transl. Gastroenterol. 2018, 9(6): e162. DOI: 10.1038/s41424-018-0030-7.

75. Langdon, A., Crook, N., Dantas, G: The effects of antibiotics on the microbiome throughout development and alternative approaches for therapeutic modulation. Genome Med. 2016, 8: 39.

76. Sanz, J.A. and Aidy, S.E: Microbiota and gut neuropeptides: a dual action of antimicrobial activity and neuroimmune response. Psychopharmacology. 2016, DOI: https://doi.org/ 10.1007/s00213-019-05224-0.

77. Lyte, M.: Probiotics function mechanistically as delivery vehicles for neuroactive compounds: Microbial endocrinology in the design and use of probiotics. BioEssays. 2011, DOI: https://doi.org/10.1002/bies.201100024.

78. Bermudez-Brito, M., Plaza-Diaz, J., Munoz-Quezada, S., Gomez-Llorente, C., Gil, A: Probiotic Mechanisms of Action. Ann. Nutr. Metab. 2012, 61(2): 160-174.

79. Fijan, S: Microorganisms with Claimed Probiotic Properties: An Overview of Recent Literature. Int. J. Environ. Res. Public Health. 2014, 11(5): 4745-4767.

80. Kechagia, M., Basoulis, D., Konstantopoulou, S., Dimitriadi, D., Gyftopoulou, K., Skarmoutsou, N., Fakiri, E.M: Health Benefits of Probiotics: A Review. ISRN Nutr. 2013, DOI: $10.5402 / 2013 / 481651$.

81. O'Callaghan, A. and Van Sinderen, D.: Bifidobacteria and Their Role as Members of the Human Gut Microbiota. Front. Microbiol. 2016, DOI: 10.3389/fmicb.2016.00925.

82. Komatsuzaki, N., Shima, J., Kawamoto, S., Momose, H., Kimura, T: Production of $\gamma$-aminobutyric acid (GABA) by Lactobacillus paracasei isolated from traditional fermented foods. Food Microbiol. 2005, 22(6): 497-504.

83. Coda, R., Rizzello, C.G., Gobbetti, M: Use of sourdough fermentation and pseudo-cereals and leguminous flours for the making of a functional bread enriched of $\gamma$-aminobutyric acid (GABA). Int. J. Food Microbiol. 2010, 137(2-3): 236-245.

84. Asano, Y., Hiramoto, T., Nishino, R., Aiba, Y., Kimura, T., Yoshihara, K., Koga, Y, et al.: Critical role of gut microbiota in the production of biologically active, free catecholamines in the gut lumen of mice. 2012, DOI: https://doi.org/10.1152/ajpgi.00341.2012.

85. Barneound, P., Rivet, J.M., Vitiello, S, Le Moal, M., Neveu, P.J: Brain norepinephrine levels after BCG stimulation of the immune system. Immunol. Lett. 1988, 18(3): 201-204.

86. Hu, J., Chen, H., Cheng, H: Effect of Direct-fed Microbials, Bacillus subtilis, on Production Performance, Serotonin Concentrations and Behavioral Parameters in a Selected Dominant Strain of White Leghorn Hens. Int. J. Poult. Sci. 2018, 17(3): 106-115.

87. Das, A., Verma, A., Mukherjee, K.J: Synthesis of dopamine in E. coli using plasmid-based expression system and its marked effect on host growth profiles. Prep. Biochem. Biotechnol. 2017, 47(8): 754-760.

88. Stephenson, M., Rowatt, E., Harrison, K: The Production of Acetylcholine by a Strain of Lactobacillus plantarum. Microbiology. 1947, 1:279-298.

89. National Institute of Health (US): Information about mental illness and the brain. NIH Cirriculum Supplementation Series, 2007. 